\title{
Interpretation of performances of hybrids obtained from 43 asparagus parent genotypes
}

\author{
JB Denis ${ }^{1 *}, \mathrm{C}$ Rameau ${ }^{2}$ \\ 1 INRA, Laboratoire de Biométrie; \\ 2 INRA, Station de Génétique et d'Amélioration des Plantes, \\ route de Saint-Cyr, F78026 Versailles Cedex, France
}

(Received 3 December 1993; accepted 2 March 1994)

\begin{abstract}
Summary - The data used were the yields of 231 distinct hybrids grown in long-term multi-site trials (10 yr, 4 sites), resulting from the crossing of 43 genotypes. Genotype-environment interaction was taken into account by means of a factorial regression model previously defined through the varieties used as controls in the trials. Two environmental covariates were used: the latitude of the site, and the type of production (green or white asparagus). It is shown in this paper that most of main effects and genotype-environment interactions could be explained by additive and symmetrical parental influences. The pseudo-diallel structure was therefore reduced to the values of 3 parameters associated with each parent (main effect and 2 regression coefficients) and could thus be easily interpreted. The model was used to evaluate yields of all 816 possible hybrids within chosen environmental conditions.
\end{abstract}

\section{Asparagus officinalis / genotype-environment interaction / diallel / series of experiments / parental effect}

Résumé - Interprétation des performances d'hybrides issus de $\mathbf{4 3}$ génotypes d'asperge. Les rendements de 231 hybrides différents constituent l'ensemble des données utilisé, provenant d'un réseau d'expérimentation comprenant 10 années et 4 lieux. Les interactions génotype-milieu sont prises en compte par le biais d'un modèle de régression factorielle établi dans un travail antérieur à partir des variétés utilisées comme témoin dans le dispositif. Deux covariables du milieu sont utilisées : la latitude du lieu et le type de production (asperge blanche ou verte) dans le lieu et l'année. On arrive à la conclusion que les effets principaux et les interactions génotype-milieu peuvent être décrites par des effets parentaux additifs et symétriques. L'interprétation du pseudo-diallèle peut donc être facilement établie grâce aux valeurs de 3 paramètres (effet principal et 2 coefficients de régression) caractérisant chacun des 43 génotypes parentaux. Enfin la valeur hypothétique des hybrides est prédite (y compris pour les hybrides non expérimentés) grâce au modèle retenu pour des conditions d'un milieu déterminé.

\section{Asparagus officinalis / interaction génotype-milieu / diallèle / réseau d'essai / effets parentaux}

\section{INTRODUCTION}

During the past 30 years, asparagus breeders have developed several types of hybrids (Corriols and Doré, 1989) ranging from highly heterogeneous populations (Bannerot et al, 1969) to genetically homogeneous $\mathrm{F} 1$ hybrids (Corriols et al, 1989). Many characteristics of asparagus make experimentation difficult and lengthy; the species is a perennial and hybrids cannot be obtained or tested simultaneously in large numbers. Indeed the yield varies greatly from year to year. In the French (INRA) breeding program, it is suggested that at least 4 years' observation is

* Correspondence and reprints 
necessary to have a reliable estimate of yield; the experiments began in 1969, the main objective being to produce homogeneous $\mathrm{F} 1$ hybrids with high yield, an early production and thick spears (the edible portion of young stems) with a good shape.

There are 2 types of asparagus produced in the world: (i) white asparagus in which the spears are harvested from raised beds just as the tip of the spear emerges through the soil; and (ii) green asparagus in which the spears are harvested at ground level once elongated to about $20-30 \mathrm{~cm}$. Any cultivar can be used for white or green asparagus. Nevertheless, in different countries, specific cultivars have been bred for each type of cultivation. In France we used to cultivate only white asparagus, which predominates in Europe, while green asparagus is common in both the United States and Italy.

During the selection process, plant breeders are faced with difficult choices. First of all, the genotype-environment interaction must be taken into account by introducing soil and climatic variability corresponding to the target regions of cultivation. This can be done by performing experiments in different environments (years and sites). When the cultivars to be produced are hybrids, however, these difficulties are increased by the enormous multiplication of possibilities from only a few potential parents. This is of course impossible and some drastic reduction must be applied.

The large quantity of heterogeneous information analysed in this study has been gathered over the last 15 years in the French (INRA) breeding program in a 4-location multisite experiment in France; it represents an exceptional set of data. An initial interpretation of these data (Corriols and Doré, 1989) based on a ranking index was used for comparing different types of hybrids. Their synthesis took into account 4 characters (total yield, early yield, spear diameter and spear appearance). The novelties introduced in this paper concern the modelling of the genotype-environment interaction and the parental effects on total yield.

In this study we examine the available data on hybrids in order to assess the values of the parents. The aim is also to know which parents can be used to produce hybrids for cultivation both in the south and north of France and/or for both white and green production. To. reach these objectives, we used a simplified model leading to 3 parameters for each of the parental genotypes. They could be used as additional help for recommending future hybrid creations.

\section{MATERIALS AND METHODS}

\section{Biology of asparagus}

Asparagus is a dioecious species (with separate male and female plants). Sex determinism is monogenic; the male plants are heterogametic $(\mathrm{Mm})$ and the female plants are homogametic recessive $(\mathrm{mm}$ ) (Rick and Hanna, 1943). Homozygous genotypes were obtained by 1 of 2 different methods.

\section{The search for haploid genotypes from polyembryonic seeds}

After chromosome doubling this method leads to female plants homozygous for all loci (Thévenin, 1968; Doré, 1977). This is the case for parents $L_{1}$ to $L 24$, which are homozygous lines composed of $50 \%$ female $(\mathrm{mm})$ and $50 \%$ male $(\mathrm{Mm})$ isogenic plants and have been produced by crossing a homozygous female plant to a male plant and back-crossing to the female recurrent parent for 5-6 generations (Thévenin and Doré, 1976). These pure lines can be used either as the male or the female parent (tables I and II).

\section{In vitro anther culture}

This method (Doré, 1974) gives either female or male homozygous plants. M1 to $\mathrm{M} 10$ are male genotypes obtained by this method. These genotypes are homogametic (MM) and are called super-males because of their all male progeny.

\section{Data}

Data were issued from the French (INRA) asparagus breeding program; their detailed environmental characteristics have been described previously by Rameau and Denis (1992). About 40 new hybrids and standard varieties were planted each year generally in 4 testing sites: 2 in the north of France, 1 in Central France and 1 in the south. Hybrids were grown in a randomized complete block design with 4 replications and 15 plants per plot. One of the northern locations and the central location produce white asparagus; the other 2 produce green asparagus. The difference to the first study is that all the hybrids are now included in the statistical analysis. There were 231 hybrids which can be presented in a pseudo-diallel scheme (table I), as some parents cannot be or were not used in both directions. The total number of parent genotypes was 43 but they were used non-randomly according to their genetic structure, their fertility and the date when they were obtained within the breeding program.

Genotypes $\mathrm{f} 1$ to $\mathrm{f} 7$ are heterozygous female plants and were used only as female parents. Genotype $\mathrm{m} 11$ and $\mathrm{m} 12$ are heterozygous male plants used only as male parents. The other 34 parents are homozygous 
Table I. Number of yields for each of the 231 hybrids. Rows (columns) correspond to female (male) parents.
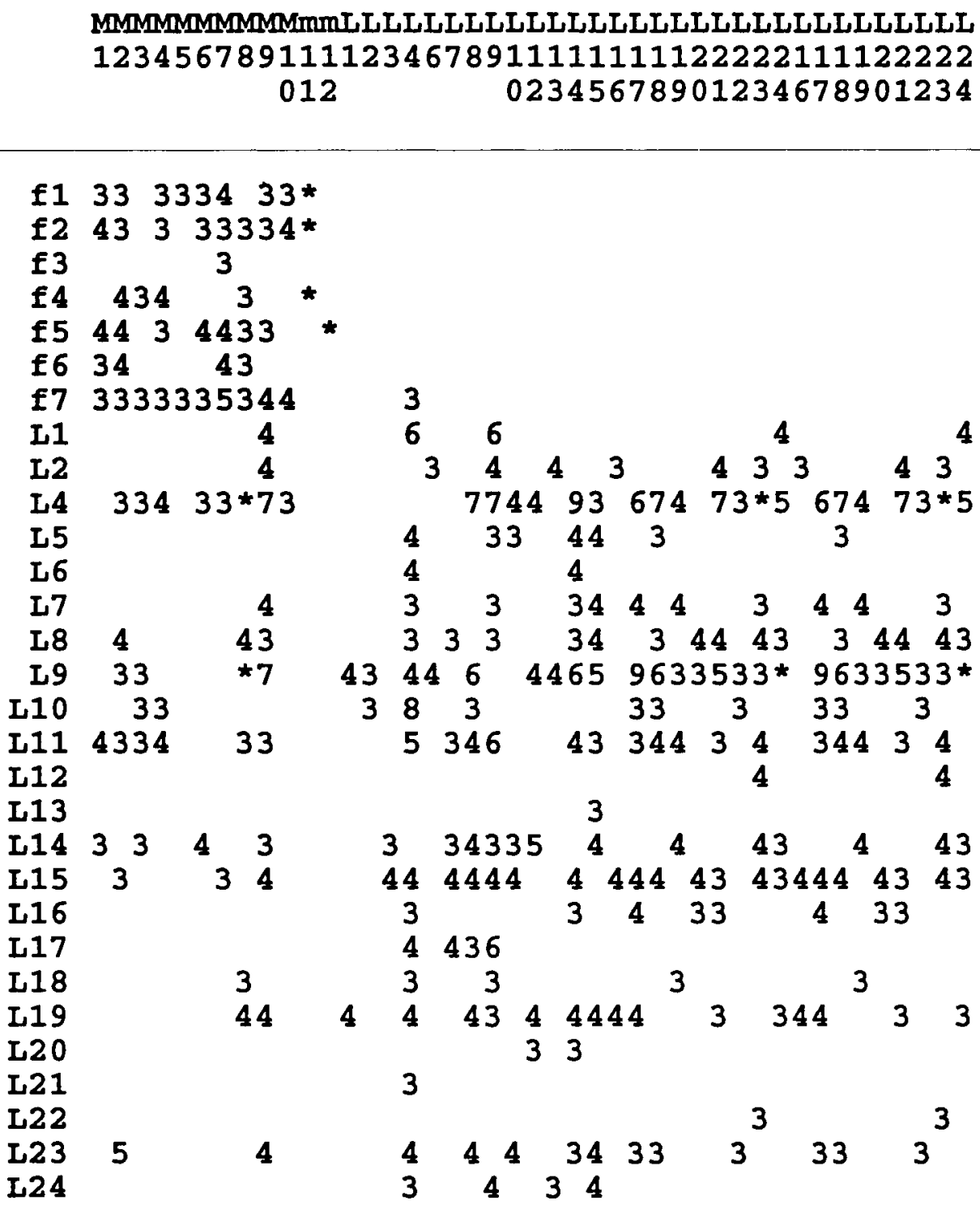

Empty cells indicate that there was no hybrid; stars indicate $>9$ replications.

genotypes; super-males ( $\mathrm{M} 1$ to $\mathrm{M} 10$ ) can only be used as male (see above); pure lines (L1 to L24) were generally used as male and female (due to sterifity problems L3 was used only as male and L5 and L11 were used only as female).

As in the previous study, the yield was estimated by the weight of harvested spears during the 4th year after planting, ie the second harvest season. Among the 7 standard varieties used to select the factorial regression model (Rameau and Denis, 1992), 5 had their parents among the 43 genotypes: 'Andréas' is an F1 hybrid between L19 and the super-male M8 (Corriols et al, 1989); 'Stéline' is a clonal hybrid between 55 and $\mathrm{m} 12$; and 'Aneto', 'Cito' and 'Desto' are clonal hybrids between $\mathrm{m} 11$ and the female plants $f 1, f 2$ and $f 4$, respectively. A clonal hybrid results from crossing between 2 (heterozygous) plants, 1 male and 1 female, multiplied by in vitro culture.

\section{Statistical methods}

Even with incomplete data, the major features of variability must be introduced in the statistical model to give an unbiased and accurate interpretation of genotype behavior. This has been done in 2 ways. First the genotype-environment interaction was modelled with the model selected by Rameau and Denis (1992), in the same series of experiments, analysing yields of 
Table II. Summary of the data set for lines with male or female parents.

\begin{tabular}{|c|c|c|c|c|c|c|c|c|c|c|c|}
\hline$-1-$ & $-2-$ & $-3-$ & $-4-$ & $-5-$ & $-6-$ & $-1-$ & $-2-$ & $-3-$ & $-4-$ & $-5-$ & $-6-$ \\
\hline M1 & 0 & & & & & M1 & 7 & 24 & 3.49 & 1.37 & 4.88 \\
\hline M2 & 0 & & & & & M2 & 12 & 42 & 4.38 & 3.10 & 7.27 \\
\hline M3 & 0 & & & & & M3 & 7 & 21 & 2.83 & 2.15 & 3.39 \\
\hline M4 & 0 & & & & & M4 & 8 & 27 & 4.09 & 2.15 & 4.98 \\
\hline M5 & 0 & & & & & M5 & 2 & 6 & 6.45 & 6.31 & 6.60 \\
\hline M6 & 0 & & & & & M6 & 6 & 20 & 3.89 & 3.73 & 4.11 \\
\hline M7 & 0 & & & & & M7 & 8 & 29 & 5.12 & 2.87 & 6.26 \\
\hline M8 & 0 & & & & & M8 & 11 & 55 & 4.92 & 2.98 & 6.19 \\
\hline M9 & 0 & & & & & M9 & 15 & 60 & 3.89 & 0.93 & 6.25 \\
\hline M10 & 0 & & & & & M10 & 4 & 14 & 3.23 & 2.51 & 3.69 \\
\hline $\mathrm{m} 11$ & 0 & & & & & $\mathrm{~m} 11$ & 3 & 75 & 3.69 & 3.07 & 4.14 \\
\hline $\mathrm{m} 12$ & 0 & & & & & $\mathrm{~m} 12$ & 1 & 25 & 3.30 & 3.30 & 3.30 \\
\hline$f 1$ & 9 & 51 & 3.89 & 2.87 & 6.60 & f 1 & 0 & & & & \\
\hline f2 & 9 & 55 & 4.25 & 3.54 & 6.06 & $f 2$ & 0 & & & & \\
\hline f 3 & 1 & 3 & 5.36 & 5.36 & 5.36 & f 3 & 0 & & & & \\
\hline $\mathrm{f} 4$ & 5 & 34 & 3.47 & 3.07 & 4.98 & $\mathrm{f} 4$ & 0 & & & & \\
\hline f 5 & 8 & 50 & 3.65 & 2.98 & 5.24 & $f 5$ & 0 & & & & \\
\hline f 6 & 4 & 14 & 3.99 & 2.17 & 5.64 & f 6 & 0 & & & & \\
\hline f7 & 11 & 37 & 4.34 & 3.39 & 6.31 & f7 & 0 & & & & \\
\hline L1 & 4 & 20 & 3.39 & 2.90 & 3.70 & LI & 2 & 8 & 3.71 & 3.69 & 3.72 \\
\hline I2 & 7 & 25 & 3.27 & 1.95 & 4.59 & L2 & 2 & 6 & 3.90 & 3.85 & 3.95 \\
\hline L3 & 0 & & & & & L3 & 2 & 7 & 3.75 & 3.50 & 4.09 \\
\hline L4 & 21 & 118 & 4.02 & 2.51 & 6.06 & L4 & 17 & 68 & 3.85 & 2.38 & 5.22 \\
\hline L5 & 6 & 21 & 2.21 & 0.76 & 3.33 & L5 & 0 & & & & \\
\hline L 6 & 2 & 8 & 2.52 & 1.95 & 3.09 & L6 & 2 & 7 & 3.44 & 2.63 & 4.05 \\
\hline L7 & 8 & 28 & 2.19 & 1.36 & 3.80 & L7 & 5 & 17 & 2.87 & 2.04 & 4.32 \\
\hline L8 & 13 & 45 & 3.27 & 2.03 & 4.96 & L8 & 9 & 39 & 3.19 & 2.46 & 3.97 \\
\hline$L 9$ & 21 & 112 & 4.36 & 2.15 & 7.27 & L9 & 13 & 55 & 3.60 & 2.40 & 4.82 \\
\hline L10 & 8 & 29 & 3.35 & 1.62 & 4.49 & L10 & 5 & 18 & 3.31 & 2.38 & 4.23 \\
\hline L11 & 17 & 63 & 3.12 & 0.76 & 4.48 & L11 & 0 & & & & \\
\hline L12 & 1 & 4 & 3.22 & 3.22 & 3.22 & L12 & 5 & 20 & 3.33 & 3.02 & 3.84 \\
\hline L13 & 1 & 3 & 2.43 & 2.43 & 2.43 & L13 & 3 & 11 & 3.20 & 1.83 & 4.38 \\
\hline L14 & 14 & 49 & 2.80 & 0.93 & 4.09 & L14 & 12 & 50 & 2.90 & 1.73 & 4.19 \\
\hline L15 & 17 & 64 & 3.37 & 2.21 & 6.39 & L15 & 11 & 42 & 2.65 & 0.76 & 4.61 \\
\hline L16 & 5 & 16 & 3.00 & 2.12 & 4.42 & L16 & 3 & 11 & 3.10 & 1.95 & 3.64 \\
\hline L17 & 4 & 17 & 4.63 & 3.90 & 5.22 & L17 & 9 & 40. & 4.30 & 2.98 & 5.40 \\
\hline L18 & 4 & 12 & 4.37 & 2.96 & 6.19 & L18 & 8 & 33 & 2.98 & 0.76 & 3.70 \\
\hline L19 & 13 & 49 & 3.30 & 2.08 & 4.83 & L19 & 6 & 22 & 3.46 & 1.36 & 5.11 \\
\hline L20 & 2 & 6 & 2.82 & 2.45 & 3.18 & L20 & 4 & 14 & 2.65 & 2.12 & 3.44 \\
\hline L21 & 1 & 3 & 4.69 & 4.69 & 4.69 & L21 & 8 & 32 & 3.28 & 2.08 & 4.27 \\
\hline L22 & 1 & 3 & 2.28 & 2.28 & 2.28 & L22 & 4 & 12 & 2.48 & 1.67 & 3.13 \\
\hline L23 & 10 & 37 & 3.32 & 1.67 & 5.40 & L23 & 10 & 48 & 2.96 & 1.40 & 4.65 \\
\hline L24 & 4 & 14 & 2.99 & 1.83 & 4.68 & L24 & 7 & 32 & 3.23 & 2.03 & 3.57 \\
\hline
\end{tabular}


control varieties which were more systematically experimented. Secondly genotype effects, main effects and interactions were simplified by retaining only the main effects associated with the parental lines of the hybrids.

Following the model selected in Rameau and Denis (1992) some more specific models using the diallel structure were fitted. Only the general model [GEN] and the model retained according to the ANOVA [RET] are reported here. Let $E\left(Y_{(f, m),(s, y)}\right)$ be the expectation of the yield of hybrid $(f, m)$, crossing female $f$ with male $m$, grown in environment $(s, y)$, defined by site $s$ in year $y$. Two models similar to those proposed by Lin et al (1977) can then be written:

$$
\begin{aligned}
& E\left(Y_{(f, m),(s, y)}\right)=\mu+e_{(s, y)}+v_{(f, m)}+c_{(f, m)^{\circ}} \operatorname{Lat}_{(s)} \\
& +d_{(t, m)} \cdot \operatorname{Prod}_{(s, y)} \\
& E\left(Y_{(t, m)}(s, y)\right)=\mu+e 1_{(s)}+e 2_{(y)}+v_{(f)}+v_{(m)}+e 3_{(s, y)} \\
& +\mathrm{c}_{(f)^{\bullet}} \text { Lat }_{(s)}+\mathrm{c}_{(m)^{\bullet}} \text { Lat }_{(s)}+\mathrm{d}_{(f)^{\bullet}} \operatorname{Prod}(s, y) \\
& +\mathrm{d}_{(m)} \cdot \operatorname{Prod}_{(s, y)}
\end{aligned}
$$

Lat $_{(s)}$ and $\operatorname{Prod}_{(s, y)}$ are, respectively, the latitude of the experimental site $s$ and the type of production ( 1 for green asparagus, 0 for white asparagus) used in site $s$ year $y ; \mu$ is the general constant; $\mathrm{e}_{(s, y)}, \mathrm{v}_{(f, m)}$, $\mathrm{e} 1_{(s)}, \mathrm{e} 2_{(y)}, \mathrm{v}_{(p)}$ are main effects; $\mathrm{e} 3_{(s, y)}$ is the interaction between site and year; $\mathrm{c}_{(f, m)}, \mathrm{d}_{(f, m)}, \mathrm{c}_{(p)}$ and $\mathrm{d}_{(p)}$ are regression coefficients depending on various factors. These parameters are unknown and were estimated from the data; here subscript $p$ is used for parent and can be $f$ or $m$ in model [RET]. Both models are similar for environmental effects because the interaction term between site and year has been retained, as well as the regression terms for latitude (Lat) and type of production (Prod). The difference is in the simplification of the parameters for the hybrids. For main effect and regression coefficients, only additive and identical mother/father effects are retained, eg, $v_{(t, m)}$ is turned into $\mathrm{v}_{(f)}+\mathrm{v}_{(m)}$. Incidentally, 2 problematic effects vanished: (i) the specific combining ability, which was not completely inspected because of the numerous missing crossings (table 1); and (ii) the maternal effect at the level of main effects, which could have been different for male and female parents $\mathrm{v} 1_{(f)}+$ $\mathrm{v} 2(m)$.

The models considered are linear fixed-effect models, ie the observations are assumed to be non-correlated, and to have identical unknown variance; they belong to the factorial regression models described by Denis $(1980,1988,1991)$. Therefore, they do not take into account the genetic relationship existing between the genotypes or the genetical heterogeneity of the types of hybrids; they must be used as approximate models. The statistical process was performed by means of Intera (Decoux and Denis, 1991) and Modli (Modulad, 1987), 2 statistical packages allowing analysis of such models with many missing values.

Finally the model [RET] was applied to predict yields of all possible hybrids even when they were not observed in a given year and in particular conditions (latitude and type of production). In fact the influence of the year was not important for comparing genotypes because both factors interact only through the type of production; we chose 1985. Southern site and green asparagus production were chosen because no specifically adapted variety was really available for these conditions. In France, traditional asparagus production is white and not located in the South. Such predictions must be used cautiously due to the fact that the model is approximate and it was not possible to calculate confidence intervals for the predictions.

\section{RESULTS}

The 990 yields that make up the data are summarized in table II. There were large differences between the lines both for the number of crossings or replications and for the yields.

Table III displays the ANOVA table of the 2 embedded models [GEN] and [RET] described above. As there were only 6 true replications (reciprocal hybrids grown twice in the same environment), these were eliminated from the sum-ofsquares decomposition and the last remainder term was used as the error term.

The results obtained here are consistent with those obtained by Rameau and Denis (1992). At the hybrid level the mean squares for genotype-environment interaction have the same order of magnitude: 0.57 (vs 0.42 in Rameau and Denis (1992)) while the MS remainder is 0.38 (vs 0.23 ). Some reduction can be noted for the MS associated with the 2 covariates: 0.72 and 0.67 (against 2.36 and 1.88) but this is understandable because in the previous study the covariates were chosen as maximizing the mean squares. On the contrary, it is worth noting that they are still highly significant and explain a substantial part of the interaction. The new result given by the retained model [RET] is that most genotype effects can be explained by additive and symmetrical parent effects.

Parameters of this model concerning genotypes are given in table IV. As in Rameau and Denis (1992), these parameters correspond to previously centered covariates in order to interpret the main effect $v_{(p)}$ independently of the other 2 regression coefficients.

From the 816 potential hybrids, the best 30 were selected to assess the best parents for green asparagus production ( $\operatorname{Prod}=1 ; 0.486$ after centering) in the south (Lat $=43.83 ;-1.286$ after centering). 
Table III. Analysis of variance combining the general model [GEN] and the retained model [RET].

\begin{tabular}{|c|c|c|}
\hline Source of variation & $D F$ & $M S$ \\
\hline Environment main effect & 34 & $35.82 * \star *$ \\
\hline Site main effect & 3 & $121.04^{\star * *}$ \\
\hline Year main effect / site main effect & 9 & $38.44^{\star \star \star}$ \\
\hline Site $\mathrm{x}$ year interaction & 22 & $23.12^{\star * *}$ \\
\hline Hybrid main effect / environment main effect & 230 & $3.47^{\star \star \star}$ \\
\hline Additive symmetrical parent effect / (site + year) main effects & 42 & $14.70^{\star \star \star}$ \\
\hline Environment $\mathrm{x}$ hybrid interaction & 719 & $0.57\left(^{\star \star}\right)$ \\
\hline Hybrid $x$ latitude & 230 & $0.72^{* \star \star}$ \\
\hline Additive symmetrical parent $x$ latitude & 42 & $2.22 * \star \star$ \\
\hline Remainder & 188 & 0.38 \\
\hline Hybrid $x$ production & 230 & $0.67^{\star \star \star}$ \\
\hline Additive symmetrical parent $\mathrm{x}$ production & 42 & $2.01^{\star \star \star}$ \\
\hline Remainder & 188 & 0.37 \\
\hline Remainder & 259 & 0.38 \\
\hline
\end{tabular}

Sources of variation of the general model are decomposed according to their selected part in the retained model inducing with the remaining part a $f$ test justifying the retained model if not significant. /: adjusted for; ${ }^{\star \star \star}$ significant at the $0.1 \%$ level, the last remainder term being taken as the error term.

\section{DISCUSSION}

The main parental effect $v_{(p)}$ (table IV) confirmed the advantage of the super-male in asparagus. The values for 5 of the super-males (out of 10) were greater than 1 . This advantage was highlighted when we compared the main parental effect of the pure line L9 $(0.520)$ and the main parental effect of the super-male M7 (1.164) obtained from this pure line by androgenesis. The same tendency was observed when we compared the main parental effects of the super-male M9 (0.232) obtained by androgenesis from the pure line L14 $(-0.564)$ with the main effect of the pure line itself. These genotypes are both homozygous (with a residual heterozygosity for the pure line); the main difference is that the super-male gives an all-male hybrid progeny whereas the pure line gives $50 \%$ female and $50 \%$ male progeny. The agronomic advantage of male plants over female plants is well known in asparagus: male plants produce more spears per plant than female plants and consequently have a higher yield (Robbins and Jones, 1926; Thévenin, 1967). Consequently, the use of super-males as the male parent is a direct way of increasing the yield and also the homogeneity of the hybrids.

The regression term $\left.\left(\mathrm{C}_{(\rho)}\right)^{\left\llcorner{ }^{L}\right.} \mathrm{Lt}_{(s)}\right)$ for the latitude of the experimental site is particularly interesting for the continuation of the breeding program (table IV). Development of hybrids for specific sites is more and more frequent in plant breeding. Low negative values indicate the parents that give hybrids with good behavior in the south of France. This is particularly true for $\mathrm{M} 3, \mathrm{~m} 12, \mathrm{~L} 5$, L6, L13 and L24. Three of these (m12, L6 and L24) are lines known to give hybrids with a relatively good early yield especially in the south of France (data not published); early yield, which is the yield cumulated in the first 6-8 harvests within a season is positively correlated with total yield. These results and empirical observations could be interpreted by the hypothesis that these hybrids do not need cold temperatures for starting growth and consequently start earlier and behave better in the south than hybrids that have high cold temperature requirements to start and to have a good yield. In previous work (Rameau and Denis, 1992), we gave examples of the wellknown varieties 'Andréas', whose superiority shows up better in the north of France, and 'Steline' which yields as much as 'Andréas' in the south and which is a particularly early yielding hybrid. The parents of 'Andréas' (L9 and M8) have a positive regression coefficient for the latitude whereas one of the parents of 'Stéline' ( 55 and $\mathrm{m} 12$ ) has a low negative value for this parameter. These hypotheses, suggested by the sta- 
Table IV. Estimated parameters of the retained model [RET] with centered covariates for each parent line.

Main * Latitude* ToProd * $^{*}$

$\begin{array}{rrrr}\text { M1 } & 0.590 & 0.300 & 0.790 \\ \text { M2 } & 1.141 & 0.153 & 0.422 \\ \text { M3 } & -0.101 & -0.742 & -0.938 \\ \text { M4 } & 1.084 & 0.362 & 0.955 \\ \text { M5 } & 1.044 & 1.212 & -1.665 \\ \text { M6 } & 0.516 & 0.173 & -0.670 \\ \text { M7 } & 1.164 & -0.015 & -1.268 \\ \text { M8 } & 1.331 & 0.510 & 0.709 \\ \text { M9 } & 0.232 & -0.173 & -0.414 \\ \text { M10 } & -0.701 & 0.159 & 0.360 \\ \text { m11 } & 0.309 & -0.127 & -0.183 \\ \text { m12 } & -0.022 & -0.702 & -0.003 \\ \text { I1 } & -0.100 & -0.045 & 0.151 \\ \text { f2 } & 0.447 & 0.310 & 0.915 \\ \text { I3 } & 0.921 & 0.803 & -0.520 \\ \text { I4 } & -0.430 & -0.143 & 0.022 \\ \text { I5 } & -0.193 & 0.294 & 0.346 \\ \text { I6 } & -0.716 & 0.027 & 0.287 \\ \text { I7 } & 0.099 & 0.265 & 0.816 \\ \text { L1 } & -0.278 & 0.248 & 0.253 \\ \text { L2 } & 0.024 & 0.081 & 0.987 \\ \text { L3 } & 0.422 & -0.084 & -0.370 \\ \text { L4 } & 0.386 & 0.306 & 0.573 \\ \text { L5 } & -1.397 & -0.562 & -0.741 \\ \text { L6 } & 0.778 & -0.480 & -0.322 \\ \text { L7 } & -1.045 & -0.347 & 0.345 \\ \text { L8 } & -0.193 & -0.470 & -0.391 \\ \text { L9 } & 0.520 & 0.495 & 0.368 \\ \text { L10 } & 0.202 & 0.401 & 0.205 \\ \text { L11 } & -0.658 & 0.368 & 0.664 \\ \text { L12 } & -0.547 & -0.123 & 0.215 \\ \text { L13 } & -0.950 & -0.738 & -0.246 \\ \text { L14 } & -0.564 & -0.200 & -0.122 \\ \text { L15 } & -0.565 & -0.143 & 0.050 \\ \text { L16 } & -0.631 & -0.111 & -0.066 \\ \text { L17 } & 0.757 & -0.266 & -0.701 \\ \text { L18 } & -0.401 & 0.205 & 0.031 \\ \text { L19 } & -0.331 & -0.170 & -0.084 \\ \text { L20 } & -0.335 & -0.170 & -0.038 \\ \text { L21 } & -0.312 & 0.029 & -0.228 \\ \text { L22 } & -0.459 & 0.263 & 0.436 \\ \text { L23 } & -0.482 & -0.274 & -0.205 \\ \text { L24 } & -0.567 & -0.882 & -0.742\end{array}$

* Main, latitude and ToProd correspond to $v_{(p)}, c_{(p)}$ and $d_{(p)}$ respectively in model [RET]. 
tistical interpretation, would require further physiological studies to be confirmed; on the other hand, early yields should be analysed more precisely.

When the parameter associated with the type of production ( $\mathrm{d}_{(\mathrm{p})}$ : table IV, col 'ToProd') is positive, the yield was greater for the green production than for the white. This parameter is to be interpreted while keeping in mind that, in the data analysed, the type of production depends on the site; fortunately, the confounding with latitude is not important because green asparagus production was represented in both the northernmost and the southernmost sites. An interesting feature is the positive covariation of $d_{(p)}$ with $c_{(p)}$ for all the parents except 3 (M7, $\{3$ and particularly M5). This general trend may explain why no variety specially adapted for green asparagus production (positive regression coefficient for the type of production) and for the south of France (negative regression coefficient for the latitude) has been commercialized from this genetic material from a relatively narrow range of sources (Geoffriau et al, 1992).

Predicted yields for the conditions chosen (the year 1985, southern site and green asparagus), vary from 0.14 (L5 x M5) to $4.89 \mathrm{~T} / \mathrm{ha}$ (L6 $\mathrm{x}$ M2). Among the best 30 predicted hybrids, the most frequent parents are L6, M2, M4, M8 and m12, which occur $9,7,6,5$ and 4 times, respectively. These results give additional support to the current breeding program for constructing new populations that are improved for different characters of breeding importance as stem number, stem diameter and early yield. Taking into account the genealogy of the parents (when known), M8 was used (with L4 and L17) to construct the population improved for stem number and consequently total yield. The 2 lines L6 and M2 with L24 are involved in the construction of the population improved for early yield and specially adapted to the south of France. M4 has not been used because it is genetically close to M2.

In the same way it would be worth analysing the determinism of early yield as well as other characters of breeding importance which have been observed in these experiments. We have made the hypothesis that early yield is certainly influenced by temperature during the rest period of the plant in winter. This is also true for spear diameter and spear number, which are yield components influenced by the type of production; green production gives thinner and more numerous spears than white production.
Despite of the poorly filled genotype $x$ environment table of data, we were able to evidence important genotype $x$ environment interactions. This was only possible by using the pseudo-diallel structure of the genotype factor, which led us to applied considerations. Once more, it must be recognized that genotype $x$ environment interactions cannot be neglected in breeding programs and that specifically adapted cultivars must be obtained.

\section{ACKNOWLEDGMENTS}

The authors thank $L$ Corriols for gathering the experimental data during her work on asparagus breeding at INRA; they are indebted to B Schweisguth for his stimulating encouragement in the course of this work; they acknowledge the reviewers for their constructive comments which clarified some important points of the paper and improved the presentation of the results.

\section{REFERENCES}

Bannerot H, Derieux M, Thévenin L, Arnoux J (1969) Résultats d'un essai comparatif de populations d'asperge. Ann Amél Plantes 19, 289-324

Corriols L, Doré C (1989) Use of rank indexing for comparative evaluation of all-male and other hybrids types in asparagus. $J \mathrm{Am}$ Soc Hortic Sci 114, 328-332

Corriols L, Doré C, Rameau C (1989) Commercial release in France of Andréas, the first asparagus all-male $\mathrm{F} 1$ hybrid! (Cobreeding INRA-DarbonneVilmorin). Acta Hortic 271, 249-252

Decoux G, Denis J-B (1991) INTERA version 3.3, Notice d'utilisation de logiciels pour l'interprétation statistique de l'interaction entre deux facteurs. Laboratoire de Biométrie, INRA, Versailles, France $175 \mathrm{p}$

Denis JB (1980) Analyse de régression factorielle. Biométrie-Praximétrie 20, 1-34

Denis JB (1980) Two-way analysis using covariates. Statistics 19, 123-132

Denis JB (1991) Ajustement de modèles linéaires et bilinéaires sous contraintes linéaires avec données manquantes. Rev Stat Appli 39, 5-24

Doré C (1974) Production de plantes homozygotes mâles et femelles à partir d'anthères d'asperge cultivées in vitro. CR Acad Sci 278, 2135-2138

Doré $C$ (1977) In vitro techniques as an efficient tool in asparagus breeding. Acta Hortic 78, 89-93

Geoffriau E, Denoue D, Rameau C (1992) Assessment of genetic variation among asparagus (Asparagus officinalis $L$ ) populations and cultivars: agromorphological and isozymic data. Euphytica 61, 169-179 
Lin CS, Binns MR, Thompson BK (1977) The use of regression methods to study genotype-environment interactions. Extending Griffing's model for diallel cross experiments and testing an empirical grouping method. Heredity 38, 309-319

Modulad (1987) MODLI, Bibliothèque Fortran 77 pour l'analyse des données. Institut de la Recherche en Informatique et Automatique, Rocquencourt, France, $522 \mathrm{p}$

Rameau C, Denis JB (1992) Characterization of environments in long-term multi-site trials in asparagus, through yield of standard varieties and use of environmental covariates. Plant Breed 109, 183-191
Rick CM, Hanna GC (1943) Determination of sex in Asparagus officinalis L. Am J Bot 30, 711-714

Robbins WW, Jones HA (1926) Sex as a factor in growing asparagus. Proc Am Soc Hortic Sci 23, 19-23

Thévenin L (1967) Les problèmes d'amélioration chez Asparagus officinalis L. I. Biologie et amélioration. Ann Amél Plantes 17, 33-66

Thévenin $L$ (1968) Les problèmes d'amélioration chez Asparagus officinalis L: II Haploïdie et amélioration. Ann Amel Plantes 18, 327-365

Thévenin L, Doré C (1976) L'amélioration de l'asperge (Asparagus officinalis $\mathrm{L}$ ) et son atout majeur, la culture in vitro. Ann Amel Plantes 26, 655-674 